\title{
Glucocorticoid receptor polymorphism in obesity and glucose homeostasis
}

\author{
Agnieszka Majer-Łobodzińska' A-D, Joanna Adamiec-Mroczek ${ }^{2, A, E, F}$ \\ ${ }^{1}$ Department and Clinic of Angiology, Hypertension and Diabetology, Wroclaw Medical University, Poland \\ ${ }^{2}$ Department and Clinic of Ophtalmology, Wroclaw Medical University, Poland \\ A - research concept and design; $\mathrm{B}$ - collection and/or assembly of data; $\mathrm{C}$ - data analysis and interpretation; \\ $D$ - writing the article; $E$ - critical revision of the article; $F$ - final approval of article
}

Address for correspondence

Agnieszka Majer-tobodzińska

E-mail: agnieszka.majer85@gmail.com

\section{Funding sources}

none declared

\section{Conflict of interest}

none declared

Received on February 27, 2015

Revised on March 26, 2015

Accepted on April 9, 2015

\begin{abstract}
Glucocorticoid receptor (GR) activity plays a significant role in the etiology of obesity and is essential for glucose homeostasis, the development of hyperinsulinaemia and subsequent increased fat deposition. Several polymorphisms in the GR gene have been described, and at least three of them seem to be associated with altered glucocorticoid sensitivity and changes in glucose homeostasis, and other metabolic parameters. The N363S polymorphism has been associated with increased sensitivity to glucocorticoides, increased insulin response to dexamethasone and increased plasma glucose level. Bcll polymorphism is associated with increased abdominal obesity, hyperinsulinaemia and increased insulin resistance. Another polymorphism, ER22/23EK, in contrast to the others, is associated with relative resistance to glucocoricides actions and more beneficial metabolic profile-lower insulin resistance level, decreased lower cardiovascular risk and subseuent prolongation of life time. More research is still needed to understand the mechanisms behind these associations at the molecular level.
\end{abstract}

Key words: obesity, glucocorticoid receptor polymorphism, N363S, BCll, ER22/23EK

DOI

$10.17219 /$ acem/41231

\section{Copyright}

Copyright by Author(s)

This is an article distributed under the terms of the

Creative Commons Attribution Non-Commercial License

(http://creativecommons.org/licenses/by-nc-nd/4.0/) 
Glucocorticoids (GCs) play an important role in regulating many basic physiological processes. These hormones are synthesized by the adrenal gland cortex and they play a key role in the majority of physiological processes, such as metabolism, immunological processes, inflammatory reactions, skeletal system development or reproduction. They are also significant in regulating the functioning of the central nervous system, the cardiovascular system and maintaining body water-electrolyte homoeostasis. Synthetic GCs constitute an important group of medicines applied in inflammatory, autoimmune and lymphoproliferative diseases treatment. Cortisol is responsible for around 95\% of steroid activity in the human body. Cholesterol, deriving mainly from low-density lipoproteins found in plasma (LDL), is the precursor in the synthesis of adrenal steroids. The regulation of endogenous GR secretion takes place at the hypothalamic-pituitary-adrenal axis. Cortisol circulates in plasma in the form bound with proteins, mainly with CBG (corticosteroid-binding globulin), less with albumins. The protein-bound form is inactive. The unbound, biologically active fraction constitutes around $3-10 \%$ of the total amount of cortisol in the vascular bed. ${ }^{1-3}$

The cortisol effect is achieved by means of glucocorticoid receptors (GRs) found in the cytoplasm, nucleus and cell membrane. These receptors belong to the nuclear receptor subfamily 3 , which are ligand-dependent transcription factors; they not only transfer the information found in the hormone molecule, but also are important transcription factors. ${ }^{1-3}$

Hormonal activity of adrenal glands seems to be an important factor in the development of hyperinsulinaemia and increased fat deposition. ${ }^{4}$ Cortisol accelerates preadipocyte differentiation by which preadipocytes become adipocytes in visceral adipose tissue (yet it inhibits their proliferation) and increases lipid storage, which leads to fat cells hypertrophy. ${ }^{5}$ In the liver, by affecting glucose6-phosphatase and phosphoenolpyruvate carboxykinase, it increases gluconeogenesis and makes liver cells more sensitive to glucagon. What is more, it induces insulin resistance by decreasing glucose uptake in peripheral tissues, which results in insulin concentration elevation in blood. ${ }^{6}$

The purpose of this paper is to present the role of glucocorticoid receptor polymorphism in obesity pathogenesis and glucose homeostasis.

\section{GC receptor composition and its gene expression}

The glucocorticoid receptor (GR) is a protein composed of 777 amino acids.

The receptor consists of several domains:

- N-terminal activation domain (AF1) that affects the activation of receptor and interaction with other transcription factors.
- Central DBD - DNA binding domain which includes zinc fingers enabling the binding of GR and DNA. The domain also contains a dimerization loop (D-loop), a sequence of 5 amino acid residues that determine the formation of dimers by active GR.

- NLS domain (nuclear localisation signal). It is a hinge region responsible for receptor translocation to the nucleus, which is involved in the conformational change of the receptor upon binding of the hormone molecule.

- LBD, ligand binding domain.

- C-terminal activation domain which enables binding with coactivator proteins. ${ }^{7-9}$

The GR receptor is found in three locations: cytoplasm, nucleus and plasma membrane. In cytoplasm, GR has the form of a monomer, which enables direct protein-protein interaction with other extranuclear regulatory proteins, and indirectly allows for gene expression change. An inactive GR in the cytoplasm is combined with the conglomerate of proteins deactivating the receptor, including chaperon proteins: hsp 90, hsp70and hsp56. ${ }^{2,8}$ In the nucleus, GR is found solely as a dimer. Both mechanisms of action, cytoplasmic and nuclear, are defined as genomic since they involve gene expression regulation. The presence of the glucocorticoid receptor has been also found in the plasma membrane. GR localized in the plasma membrane operates in a nongenomic mechanism by means of rapid changes in the activity of various signal transduction pathways. ${ }^{10}$

GRs are encoded by a single gene located on chromosome 5 (region $5 \mathrm{q} 31 \mathrm{p}$ ). ${ }^{1}$ Post-transcriptional processing leads to the formation of two receptor isoforms: $\alpha$ and $\beta$. They differ in length of the polypeptide chain and binding abilities. Isoform $\alpha$ is an active form of the receptor that binds GCs. Isoform $\beta$ cannot bind the hormone; however, it may bind DNA, thus downregulating genes by blocking the binding site for active isoform $\alpha$. Clinically, this may result in secondary resistance to GCs. ${ }^{11}$ Inflammatory process may increase $\beta$ isoform expression. It has been shown that pro-inflammatory cytokines IL-1, IL-2, IL-4, IL-13, TNF $\alpha$ particularly strongly activate the mechanisms of alternative splicing. Originally, GR $\beta$ is present in the nucleus regardless of the activation state of the receptor. If GR $\alpha$ is missing, GR $\beta$ is transcriptionally inactive. However, if both isoforms undergo expression in the same cell, GR $\beta$ acts as an activity inhibitor for GR $\alpha .{ }^{11}$ Hence, a hypothesis has been put forward that the reduced sensitivity to glucocorticoid may result from an excessive expression of $\beta$ isoform of the receptor.

\section{Glucocorticoid receptor polymorphism}

Most glucocorticoid activity is triggered by a glucocorticoid receptor. Sensitivity to glucocorticoid hormones differs among individuals. However, an individual response to GCs is quite stable, which has been proven by 
the experiment with the use of dexamethasone suppression test. ${ }^{12}$ Many studies show that this is connected with GR gene polymorphism. So far, several different polymorphisms have been identified. Some of them seem to be related to changeable sensitivity to GCs, obesity and changes in glucose homeostasis.

\section{Polymorphism N363S}

One of the most often described polymorphisms in literature is N363S. It results from a transition in exon 2 of GR gene in codon 363 - substitution of adenine with guanine, which leads to the substitution of asparagine with serine in the polypeptide chain of GR receptor. The relationship between N363S polymorphism and obesity has been shown by Huezinga et.al. ${ }^{13}$ It was demonstrated that carriers (heterozygote individuals) of this polymorphism have a higher body mass index (BMI) in comparison to individuals without this polymorphism ("wild-type" individuals). In addition, it was shown that N363S polymorphism is related to increased sensitivity to GR in vivo, which has been confirmed in the suppression test of cortisol secretion after administration of a small dose $(0.25 \mathrm{mg})$ of dexamethasone. This research also showed that fasting glucose levels before dexamethasone administration were similar in the group of N363S carriers and in the group of wild-type individuals, but after the administration of $1 \mathrm{mg}$ of dexamtehasone it was stated that the level of plasma insulinaemia increased significantly among the carriers of the described polymorphism in comparison with the control group. In an analogous study with a smaller dose of dexamethasone $(0.25 \mathrm{mg})$ in the control group, insulin concentration decreased slightly, while in the group of N363S carriers average insulin concentration increased. It was assumed that low steroid dose in the carriers of N363S polymorphism forces insulinaemia growth in order to maintain the correct glycemia. This further indicates that the carriers of N363S polymorphism are more sensitive to glucocorticoid.

Lin et al. ${ }^{14}$ showed a strong relationship between obesity and the described polymorphism. The subjects were divided into 2 groups - persons with correct arterial pressure whose parents did not suffer from arterial hypertension and persons with primary hypertension whose parents also suffered from this disease. The frequency of allele Ser 363 occurrence in both groups was similar at the level of $7.4 \%$. However, the research revealed a clear relationship of allele Ser 363 with incorrect body mass among the analyzed patients. Among patients with correct body mass, this allele was rarely found (only in $1.8 \%$ of people). All homozygotes (100\%) for this polymorphism were characterized by an increased body mass. N363S variant was present in $83 \%$ of the subjects suffering from arterial hypertension and overweight. Moreover, it has been demonstrated that this effect is allele-dependent; homozygotes, analyzed for the pres- ence of this allele, were characterised by an increased BMI in comparison to heterozygotic individuals. ${ }^{14}$

Also the research conducted by Di Blasio's ${ }^{15}$ team confirmed the relationship between obesity and glucocorticoid receptor genotype. Patients with obesity were examined (mean BMI $45.9 \pm 0.9 \mathrm{~kg} / \mathrm{m}^{2}$ ) and 106 patients with correct body mass. In the group of patients with obesity, $10 \%$ were diagnosed with type 2 diabetes, successfully controlled with a proper diet. Similarly to previous studies, ${ }^{13}$ the fasting glycemia and insulin sensitivity assessed using QUICKI, Quantitative Insulin Sensitivity Check Index $^{16}$ were similar for allele Ser 363 carriers and wild-type individuals. Di Blasio et al., ${ }^{15}$ on the basis of their observations, tried to explain pathophysiological role of N363S polymorphism in the development of obesity by speculating that increased sensitivity of carriers of this genetic variant to glucocorticoids may lead to an increased insulin secretion in response to hormonal stimulus, which in theory may underlie the increased lipogenesis and possible subsequent body mass increase.

The relationship between N363S polymorphism and an increased body mass has been questioned by Rosmond et al., ${ }^{17}$ who did not find any relationship between BMI and GR genotype. Similar conclusions were drawn from the analyses of Dobson et al. ${ }^{18}$ conducted on the Caucasian population. The authors did not demonstrate the relationship between the presence of N363S and increased body mass. However, they confirmed higher values of WHR (waist-to-hip ratio) among men who were heterozygotic for the described allele.

In 2006, Marti et al. ${ }^{19}$ published a meta-analysis of the effect N363S polymorphism has on obesity among people. The study was based on research conducted among the Spanish and German population. Also, an attempt was made to summarize data from previously published 12 studies. The total number of subjects in this study was 5,909 from different countries in the world. The analysis of the collected data proved that the carriers of N363S polymorphism in BMI $<27 \mathrm{~kg} / \mathrm{m}^{2}$ group were characterized by elevated BMI values. The comparison of persons suffering from obesity and those with correct body mass did not show any statistically significant differences in BMI between the carriers of the described polymorphism and those with the consensus genotype. In Europe, the frequency of homo- and heterozygotes carrying the described polymorphism was between $4-6 \%$ in the German, Spanish, French and British populations, and between $9-15 \%$ in the Swedish and Danish populations. Yet, the frequency of allele $363 \mathrm{~S}$ in the Australian population was between 12-13\% among individuals with the correct body mass and $26-27 \%$ in people with obesity. It was surprising to learn that $363 \mathrm{~S}$ variant of GR receptor in German and British populations is more often found among individuals with correct body mass than among those with obesity. ${ }^{20}$ In the Polish population, the frequency of allele $363 \mathrm{~S}$ is estimated at the level of $10 \% .^{21}$ 


\section{Polymorphism Bcll}

Another variant of glucocorticoid receptor is RFLP (restriction fragment length polymorphism) BclI. This term derives from the restriction enzyme used for its identification. This type of polymorphism results from a substitution of nucleotides in exon 2, cytosine-guanine transversion. ${ }^{22}$ The population of healthy non-atopic people in Poland has been identified with BclI polymorphism: GG, GC and CC with frequencies of $12.9,47.1,40.0 \%$ respectively. ${ }^{21}$

First studies conducted by Weaver et al. ${ }^{23}$ showed the relationship between the presence of the altered allele and glucose homeostasis. Among homozygotes $4.5 \mathrm{~kb}$ (GG) a significant increase of fasting insulin concentration and elevated values of HOMA factor were observed in comparison to the group of homozygotes $2.3 \mathrm{~kb}(\mathrm{CC})$ and heterozygotes CG (2.3/4.5 kb). The frequency of altered genotypes was similar in both analyzed groups. The authors put forward the hypothesis that the presence of BclI polymorphism may directly influence glucocorticoid receptor gene expression or may be connected with the modulation of transcriptional activity of genes encoding proteins responsible for maintaining glucose homeostasis.

Other studies have identified the relationship between the described polymorphism and abdominal obesity, but not general obesity. ${ }^{24-26}$ On the basis of many studies, it may be stated that this effect is allele-dependent-mutation of one allele has a different effect than homozygosity. During a 12-year observation in the study conducted by Tremblay et al., ${ }^{27}$ it was demonstrated that heterozygotic carriers of allele $\mathrm{G}(2.3 / 4.5 \mathrm{~kb})$ present with an increased tendency to accumulate adipose tissue in comparison to homozygotes for both alleles. In the study containing data from two Dutch cohort studies (the Hoorn and CODAM), Geelen et al. ${ }^{28}$ revealed that homozygous carriers of the $G$ allele have significantly greater total body fatness, BMI and increased insulin resistance. The same conclusion came out of a study carried out on children suffering from obesity. X-ray absorptiometry examination (allows for more precise investigations than anthropometric measures) revealed that homozygous carriers (GG) had an increased whole-body fat mass. ${ }^{29}$ The Bcll variant is also associated with a lower frequency of insulin resistance in women with polycystic ovary syndrome. ${ }^{30}$ These facts may support the hypothesis that BclI polymorphism has negative metabolic implications. The clinical significance of screening glucocorticoid gene polymorphism may be useful for identifying subgroups of patients at-risk who would benefit the most from personalized treatment.

\section{Polymorphism ER22/23EK}

Yet another type of polymorphism of glucocorticoid receptor is caused by two point mutations. The first one is GAG --> GAA transition. It is found in codon 22 and does not cause any changes in polypeptide chain since both codons encode glutamic acid. The other mutation, AGG---> AAG transition, takes place in codon 23 and leads to the substitution of arginine with lysine in the receptor's polypeptide chain. ${ }^{31}$ The in vivo studies showed that the carriers of this polymorphism, as opposed to broadly described N363S polymorphism, have beneficial metabolic profile due to their lower sensitivity to glucocorticoid influence. ${ }^{32}$ In the study of van Rossum, ${ }^{32}$ conducted in 202 elderly individuals, 18 heterozygotes were identified (8.9\%) for ER22/23EK allele. A suppression test with dexamethasone was conducted twice. The doses were $0.25 \mathrm{mg}$ and $1 \mathrm{mg}$. The aim was to compare plasma concentrations of cortisol and insulin between the carriers of the described polymorphism and individuals with wild genotype. After administering $1 \mathrm{mg}$ of dexamethasone in the group of ER22/23EK carriers, increased levels of plasma cortisol concentration were observed. What is more, the carriers of this mutation present with a lower concentration of insulin while fasting and lower insulin resistance factors as well as LDL cholesterol concentration. It was agreed that the carriers of ER22/23EK allele are more resistant to corticosteroid influence, which is reflected in a beneficial metabolic profile. What is more, the presence of this polymorphism results in lower insulin concentration and glycemia before and after $1 \mathrm{mg}$ dexamethasone suppression test, which are most probably the consequence of relative resistance to glucocorticoid influence. Lower values of HOMA-IR factor characterize the carriers of this allele and indicate a higher individual sensitivity to insulin. ${ }^{32}$

Van Rossum et al. ${ }^{33}$ made an attempt at analyzing a well-known effect of glucocorticoids on adipose tissue redistribution and reduction of muscle mass in the context of ER22/EK23 polymorphism. This mechanism of adrenal gland cortex hormones activity plays an important role in the lipid metabolism. It is directly related to insulin sensitivity, development of potential glucose homeostasis disorders, and, in consequence, it strongly influences general cardio-vascular risk. The authors, for 23 years, were observing a group of 350 people (aged 13-36) in order to compare anthropometric parameters between the carriers of the described gene polymorphism and wild genotype carriers. The percentage of ER22/EK23 allele carriers was similar to the one from the previous study and it reached $8 \%$. It was proven that the carriers of this polymorphism are taller, have more non-adipose body mass, bigger thigh size and more muscle strength. No difference in BMI or adipose mass was noticed in both groups. Among females, lower WHR indicator was observed. ${ }^{33}$

A detailed mechanism of such activity on the molecular level is still unknown. Amino acids sequence change may result in alterations to the quaternary receptor structure. Due to the fact that codons are located closely to transactivating domain, the above change may influence the activation or repression of the target genes. This effect may 
Table 1. Relationship of individual polymorphisms and fasting glucose concentration, insulin concentration, insulin resistance, body mass and general cardio-vascular risk

\begin{tabular}{|c|c|c|c|c|c|}
\hline Polymorphism & $\begin{array}{l}\text { Fasting glucose } \\
\text { concentration }\end{array}$ & $\begin{array}{l}\text { Insulin } \\
\text { concentration }\end{array}$ & Insulin resistance & Body mass & $\begin{array}{l}\text { General cardio- } \\
\text {-vascular risk }\end{array}$ \\
\hline Polymorphism N363 & & 个(Huezinga 1998) & & $\begin{array}{l}\uparrow(\text { Huezinga 1998, Lin 1999, } \\
\text { di Blasio 2003)/no infuence } \\
\text { (Rosmond 2001) }\end{array}$ & \\
\hline Polymorphism Bcll & $\uparrow($ Weaver 1992) & $\uparrow($ Weaver 1992) & $\begin{array}{l}\uparrow(\text { Weaver 1992) } \\
\uparrow(\text { Gleene 2013) }\end{array}$ & $\begin{array}{c}\uparrow \text { (Rosmond 2000), } \\
\uparrow \text { Tremblay et al. } \\
\uparrow \text { Gleene } 2013 \\
\uparrow \text { Barat } 2012\end{array}$ & \\
\hline $\begin{array}{l}\text { Polymorphism } \\
\text { ER22/23EK }\end{array}$ & & $\downarrow$ (van Rossum 2002) & $\downarrow$ (van Rossum 2002) & $\downarrow$ WHR (van Rossum 2004) & $\begin{array}{l}\downarrow \text { (van Rossum 2004, } \\
\text { Kuningas 2006) }\end{array}$ \\
\hline
\end{tabular}

be also connected with changes in the secondary receptor structure, which, in turn, may influence a more frequent presence of GR $\beta$ form, and at the same time, may explain lower sensitivity to glucocorticoids. ${ }^{34}$

Observations among the Danish community say that the frequency of ER23/22EK allele presence goes up with age. What is more, this genotype variant may decide about the prolongation of life. ${ }^{35}$ The study encompassing a group of elderly individuals showed that among individuals with the wild genotype, in the 4-year observation period, the percentage of deaths was $19.2 \%$, while in the group of the described allele carriers, everybody survived the observation period. Lower levels of C-reactive protein (CRP), lower total cholesterol concentration and LDL fractions were also observed in the examined population. Better cardiovascular profile may be connected with a beneficial metabolic profile and lower inflammatory activity. It is also important to highlight the higher percentage of non-adipose body mass, which is related to better insulin sensitivity and is an important factor in reducing general cardio-vascular risk.

In 2006, Kuningas et al. ${ }^{36}$ published research results about the influence of polymorphism of GR receptor on the general cardio-vascular risk in the group of people over 85. The carriers of ER23/22EK mutation showed higher levels of $\mathrm{HbA} 1 \mathrm{C}$ than individuals with the wild genotype. Additionally, these patients were diagnosed with elevated levels of CRP. No influence on the increased or lowered cardio-vascular risk or increased mortality in any of the groups was indicated.

Dutch authors, ${ }^{37}$ on the basis of 19-year-long observation of a group of children born pre-term, before the $32^{\text {nd }}$ week, demonstrated that the presence of the described allele is connected with a lower fasting insulin concentration and lower values of insulin resistance indicators. It was also said that children born pre-term, the carriers of ER23/22EK allele, were catching up with height deficiencies before the age of one, and their final height was similar to the average height of the population. In the group of pre-term children with the wild genotype, the final height was, on average, one half the standard deviation smaller. Both the equality of height and lower insulin levels seem to corroborate the hypothesis on relative resistance of ER22/23EK genotype carriers to GCs effect. ${ }^{37}$

The described polymorphisms in GR receptor gene may significantly contribute to the observed diversity in sensitivity to endo- and exogenous glucocorticoids. In Table 1 we show relationships of individual polymorphisms and fasting glucose concentration, insulin concentration, insulin resistance, body mass and general cardio-vascular risk due to cited studies. The summarized data may suggest that the analysis of GR gene sequence could be a risk indicator for certain diseases, including diseases connected with glucose homeostasis and obesity, as well as a predictor of response to GR treatment and adverse events, such as glucose homeostasis disorders in the treatment with adrenal gland cortex hormones. These findings, however, require additional research in order to verify their clinical importance.

\section{References}

1. Koper JW, van Rossum EF, van den Akker EL. Glucocorticoid receptor polymorphisms and haplotypes and their expression in health and disease. Steroids. 2014; 92: 62-73.

2. DeRijk RH, Schaaf M, de Kloet ER. Glucocorticoid receptor variants: Clinical implications. J Steroid Biochem. 2002;81:103-122.

3. Kadmiel M, Cidlowski JA. Glucocorticoid receptor signaling in health and disease Trends Pharmacol Sci. 2013;34:518- 530.

4. Bjorntorp P, Rosmond R. Obesity and cortisol. Nutrition. 2000;16: 924-936.

5. Hauner $H$, Schmid P, Pfeiffer EF. Glucocorticoids and insulin promote the differentiation of human adipocyte precursor cells into fat cells. J Clin Endocrinol Metab. 1987;64:832-835.

6. Whorwood CB, Donovan SJ, Flanagan D, et al. Increased glucocorticoid receptor expression in human skeletal muscle cells may contribute to the pathogenesis of the metabolic syndrome. Diabetes 2002;5:1066-1075.

7. Giguere V, Hollenberg SM, Rosenfeld MG, et al. Functional domains of the human glucocorticoid receptor. Cell. 1986; 46:645-652.

8. Duma D, Jewell CM, Cidlowski JA. Multiple glucocorticoid receptor isoforms and mechanisms of post-translational modification. J Steroid Biochem. 2006;102(1):11-21.

9. Rousseau GG. Structure and regulation of the glucocorticoid hormone receptor. Mol Cell Endocrinol. 1984;38:1-11.

10. Wehling M. Specific, nongenomic actions of steroid hormones. Annu Rev Physiol. 1997;59:365-393.

11. Oakley $\mathrm{RH}$, Jewell $\mathrm{CM}$, Yudt MR, et al. The dominant negative activity of the human glucocorticoid receptor beta isoform. Specificity and mechanisms of action J Biol Chem. 1999;274(39):2785727866. 
12. Huizenga NA, Koper JW, de Lange $P$, et al. Interperson variability but intraperson stability of baseline plasma cortisol concentrations, and its relation to feedback sensitivity of the hypothalamopituitary-adrenal axis to a low dose of dexamethasone in elderly individuals. J Clin Endocrinol Metab. 1998;83(1):47-54.

13. Huizenga NA, Koper JW, De Lange $P$, et al. A polymorphism in the glucocorticoid receptor gene may be associated with an increased sensitivity to glucocorticoids in vivo. J Clin Endocrinol Metab. 1998;83(1):144-151.

14. Lin RC, Wang WY, Morris BJ. High penetrance, overweight, and glucocorticoid receptor variant: Case-control study. Brit Med J. 1999;319(7221):1337-1338.

15. Di Blasio AM, van Rossum EF, Maestrini S, et al. The relation between two polymorphisms in the glucocorticoid receptor gene and body mass index, blood pressure and cholesterol in obese patients. Clin Endocrinol (Oxf). 2003;59:68-74.

16. Katz A, Nambi SS, Mather K, et al. Quantitative insulin sensitivity check index: A simple, accurate method for assessing insulin sensitivity in humans. J Clin Endocrinol Metab. 2000;85(7):2402-2410.

17. Rosmond R, Bouchard C, Bjorntorp P. Tsp509l polymorphism in exon 2 of the glucocorticoid receptor gene in relation to obesity and cortisol secretion: Cohort study. B Med J. 2001;322:652-653.

18. Dobson MG, Redfern CP, Unwin N, Weaver JU. The N363S polymorphism of the glucocorticoid receptor: Potential contribution to central obesity in men and lack of association with other risk factors for coronary heart disease and diabetes mellitus. J Clin Endocrinol Metab. 2001;86:2270-2274.

19. Marti A, Ochoa C, Sánchez-Villegas A, Martinez JA. Meta-analysis on the effect of the N363S polymorphism of the glucocorticoid receptor gene (GRL) on human obesity. BMC Med Genet. 2006;7:50.

20. Buemann B, Black E, Holst $C$, et al. The N363S polymorphism of the glucocorticoid receptor and metabolic syndrome factors in men. Obes Res. 2005;13:862- 867.

21. Panek M, Kupryś-Lipińska I, Pietras T, et al. Polimorfizm genu receptora glikokortykosteridowego h-GR/NR3C1 w populacji polskiej. http://www.mojaastma.org.pl/files/polimorfizm_genu_recept_ gliko_w_pop_pol.pdf.

22. van Rossum EF, Koper JW, Arp P, et al. Identification of the Bcl I Polymorphism in the Glucocorticoid Receptor Gene: association with sensitivity to glucocorticoids in vivo, and body mass index. Clin Endocrinol. 2003;59(5):585-592.

23. Weaver JU, Hitman GA, Kopelman PG. An association between a $\mathrm{BCl} 1$ restriction fragment length polymorphism of the glucocorticoid receptor locus and hyperinsulinaemia in obese women. $J \mathrm{Mol}$ Endocrinol. 1992;9(3):295-300.

24. Buemann B, Vohl MC, Chagnon M, et al. Abdominal visceral fat is associated with a Bcll restriction fragment length polymorphism at the glucocorticoid receptor gene locus. Obes Res. 1997;5:186-192.
25. Rosmond R, Holm G. A 5-year follow-up study of 3 polymorphisms in the human glucocorticoid receptor gene in relation to obesity, hypertension, and diabetes. J Cardiometab Syndr. 2008;3(3):132-135.

26. Giordano R, Marzotti S, Berardelli R, et al. Bcll polymorphism of the glucocorticoid receptor gene is associated with increased obesity, impaired glucose metabolism and dyslipidemia in patients with addison's disease. Clin Endocrinol (Oxf). 2012;77:863-870.

27. Tremblay A, Bouchard L, Bouchard C, et al. Long-term adiposity changes are related to a glucocorticoid receptor polymorphism in young females. J Clin Endocrinol Metab. 2003;88(7):3141-145.

28. Geelen CC, van Greevenbroek MM, van Rossum, et al. Bcl I Glucocorticoid receptor polymorphism is associated with greater body fatness: The Hoorn and CODAM studies. J Clin Endocrinol Metab. 2013;98(3):E595-E599.

29. Barat P, Corcuff JB, Tauber M, et al. Associations of glucocorticoid receptor and corticosteroid-binding globulin gene polymorphisms on fat mass and fat mass distribution in prepubertal obese children. J Physiol Biochem. 2012;68:645-650.

30. Maciel GAR, Moreira RP, Bugano DD, et al. Association of glucocorticoid receptor polymorphisms with clinical and metabolic profiles in polycystic ovary syndrome. Clinics 2014;69(3):179-184.

31. Murray JC, Smith RF, Ardinger HA, Weinberge C. RFLP for the glucocorticoid receptor (GRL) located at 5q11-5q13. Nucleic Acids Res. 1987; 15:6765

32. van Rossum EFC, Koper JW, Huizenga NA, et al. A polymorphism in the glucocorticoid receptor gene, which decreases sensitivity to glucocorticoids in vivo, is associated with low insulin and cholesterol levels. Diabetes. 2002;51(10):3128-3131

33. van Rossum EFC, Voorhoeve PG, te Velde SJ, et al. The ER22/23EK polymorphism in the glucocorticoid receptor gene is associated with a beneficial body composition and muscle strength in young adults. J Clin Endocrin Metab. 2004;89(8):4004-4009.

34. Russcher H, Lamberts SWJ, van Rossum EFC, et al. Impaired translation of glucocorticoid receptor mRNA as a result of the ER22/23EK polymorphism. Program of the $85^{\text {th }}$ Annual Meeting of The Endocrine Society. Philadelphia, PA; 2003:315 (Abstract P2-31).

35. van Rossum EFC, Feelders RA, Van Den Beld AW, et al. Association of the ER22/23EK polymorphism in the glucocorticoid receptor gene with survival and C-reactive protein levels in elderly men. Am J Med. 2004;117(3):158-162.

36. Kuningas $M$, Mooijaart SP, Slagboom PE, et al. Genetic variants in the glucocorticoid receptor gene (NR3C1) and cardiovascular disease risk. The Leiden 85-plus study. Biogerontology. 2006;7:231238.

37. Finken $\mathrm{MJ}$, Meulenbelt I, Dekker FW, et al. The $23 \mathrm{~K}$ variant of the R2 3K polymorphism in the glucocorticoid receptor gene protects against postnatal growth failure and insulin resistance after preterm birth. J Clin Endocrinol Metab. 2007;92:4777-4782. 